\title{
TRILHAS SENSITIVAS E INTERPRETATIVAS COMO PROCESSO DE FORMAÇÃO ECOLÓGICA DE ESTUDANTES DE ENSINO FUNDAMENTAL
}

\author{
Évelyn Pozzebom Barbon ${ }^{1}$ \\ Derli Juliano Neuenfeldt ${ }^{2}$
}

\begin{abstract}
Resumo: Essa pesquisa, de caráter qualitativo, objetivou analisar contribuiçóes de vivências em trilhas sensitivas e interpretativas em relação à formação ambiental de estudantes do $5^{\circ}$ ano do Ensino Fundamental de uma escola da cidade de Lajeado/RS/BRA. Para a coleta de dados, foi utilizado um questionário aplicado aos estudantes, diário de campo, registros fotográficos, cartazes e gravaçóes de áudio das rodas de conversas. Constatou-se que as vivências com a natureza podem ser um caminho que contribui na formação ecológica dos estudantes. Concluiu-se que as trilhas são significativas e o corpo revela-se como lugar possível de aprendizagens e de sensibilização da relação homem-natureza.
\end{abstract}

Palavras-chave: Educação Física. Trilhas. Educação Ambiental.

\section{SENSITIVE AND INTERPRETATIVE TRACKS AS AN ECOLOGICAL TRAINING PROCESS OF FUNDAMENTAL TEACHING STUDENTS}

\begin{abstract}
This research is characterized as qualitative, and had as objective to analyze contributions of experiences in sensitive and interpretative tracks in relation to the environmental training of students of the 5 th year of primary education at a school in the city of Lajeado/RS/BRA. For the data collection, a questionnaire was applied to the students, field diary, photographic records, posters and audio recordings of the conversation wheels. It is said that experiences with nature has shown that it can be a way to contribute to the ecological formation of students. It was concluded that thacks were significant and the body reveals to be a possible site for learning and awareness of the relationship man-nature.
\end{abstract}

Keywords: Physical Education; Tracks; Environmental Education.

1 Universidade do Vale do Taquari - Univates. Graduada em Educação Física - Licenciatura. evelyn.barbon@universo.univates.br

2 Universidade do Vale do Taquari - Univates/Brasil. Doutor em Ciências: Ambiente e Desenvolvimento. Professor e Coordenador do Curso de Educação Física - Licenciatura da Univates/Brasil.derlijul@univates.br 


\title{
PISTAS SENSIBLES Y INTERPRETATIVAS COMO PROCESO DE FORMACIÓN ECOLÓGICA DE ESTUDIANTES DE ENSEÑANZA FUNDAMENTAL
}

\begin{abstract}
Resumen: Esta investigación se caracteriza como cualitativa, y tuvo como objetivo analizar contribuciones de vivencias en pistas sensibles y interpretativas en relación a la formación ambiental de estudiantes del $5 .^{\circ}$ ańo de la Enseńanza Fundamental de una escuela de la ciudad de Lajeado / RS / BRA. Para la recolección de datos se utilizó un cuestionario aplicado a los estudiantes, diario de campo, registros fotográficos, carteles y grabaciones de audio de las ruedas de conversaciones. Se contesta que vivencias con la naturaleza puede ser un camino para contribuir en la formación ecológica de los estudiantes. Se concluyó que las pistas fueron significativas y el cuerpo se revela como lugar posible de aprendizajes y de sensibilización de la relación hombre-naturaleza.
\end{abstract}

Palabras clave: Educación Física; Pistas; Educación Ambiental.

\section{APRESENTANDO OS PROPÓSITOS DA CAMINHADA}

O meio ambiente tem sofrido muitas alterações no decorrer das últimas décadas, provocadas principalmente pelas ações humanas, tendo como consequência uma grave crise ambiental. Essa crise tem raízes na concepção antropocêntrica, construída na Idade Moderna, que colocou o homem no centro do Universo e passou a não mais reconhecê-lo como elemento integrado à natureza. A natureza, por sua vez, tornou-se objeto manipulado e descartado quando não se faz mais necessário, sem preocupação com as consequências e com as gerações futuras.

Esta compreensão de homem e de natureza é determinante da crise ambiental instaurada. Para Grün (2011), a partir dessa concepção antropocêntrica, de dominador da natureza, o homem colocou-se fora dela e passou a explorá-la como fonte inesgotável de recursos em prol de um almejado progresso econômico, que está muito longe de poder ser considerado universal. Também Giddens (1996) menciona que a objetificação da natureza e a busca do progresso econômico (crescimento) geraram consequências desastrosas para o planeta.

Além disso, contribui para a ruptura entre homem e natureza a valorização exacerbada da racionalidade. Segundo Santin (1996), para a modernidade, o humano do homem não está no corpo, mas na mente, na psique, na alma, na inteligência, na consciência. Contudo, "o corpo é o lugar onde o especificamente humano habita e se constitui, onde ele se esconde e se manifesta, mas o corpo parece ser apenas um momento, uma condição, uma transitoriedade do ser humano, nunca seu ponto central, isto é, seu modo de ser" (SANTIN, 1996, p. 83).

A desvalorização do corpo enquanto lugar de aprendizagens é reforçada na educação formal, que se preocupa principalmente com a educação da razão. Dessa forma, interessa a construção de um corpo produtivo frente aos olhos da sociedade do trabalho e do consumo ou de um corpo capaz de contribuir com o desenvolvimento intelectual. Consequentemente, reforça-se o distanciamento do 
homem em relação ao contato direto com a natureza na medida em que "sentir" tem pouco espaço na educação contemporânea.

De acordo com Matarezi (2001), esse distanciamento começa na infância, quando, para a maioria das crianças, predomina a vida urbana, o que prejudica a percepção ambiental e dificulta a elaboração de uma compreensão própria acerca dos fenômenos naturais e dos problemas ambientais que vivemos. Por isso, a formação de sujeitos com consciência ecológica, a partir de vivências com a natureza explorando os sentidos corporais, tem sido defendida por diversos autores (NEUENFELDT, 2016; SILVA; FIGUEIREDO, 2011; CORNELL, 2008; MATAREZI, 2001).

É necessário desenvolver e utilizar no ensino formal metodologias que proporcionem aos estudantes vivências com a natureza, auxiliando-os a repensarem seus modos de conviver e de agir, pois as crianças, hoje, conhecem o mundo virtualmente por meio das tecnologias de informação e de comunicação. Consequentemente, há o empobrecimento do mundo vivido e das experiências diretas com a natureza. A respeito dessa constatação, Alves (1999, p. 132) diz que "há crianças que nunca viram uma galinha de verdade, nunca sentiram o cheiro de um pinheiro, nunca ouviram o canto do pintassilgo e não tem prazer em brincar com a terra. Pensam que a terra é sujeira. Não sabem que terra é vida”.

Por isso, a Educação Ambiental, que já tem uma caminhada no uso de vivência com a natureza em processos formativos, de acordo com Medeiros (2011), tem muito a contribuir no ensino formal, para a formação de cidadãos conscientes, aptos para decidirem e atuarem na realidade socioambiental de modo comprometido com a vida, com o bem-estar de cada um e da sociedade. Também, Carvalho (2008) ressalta que a Educação Ambiental, como ação educativa, tem sido importante mediadora entre o contexto educacional e o campo ambiental, dialogando com os problemas gerados pela crise socioambiental, produzindo reflexões, concepções, métodos e experiências que buscam construir novas bases de conhecimento e valores ecológicos para esta e para as futuras gerações.

Logo, para o desenvolvimento dessa pesquisa, buscou-se uma proposta de formação ambiental a partir de trilhas sensitivas e interpretativas. Elas, além de estimularem e aguçarem os sentidos, são ricas por promoverem reflexões acerca de valores, emoções e da relação que estabelecemos com o lugar onde vivemos.

É importante sensibilizar as pessoas acerca dos problemas ambientais de forma diferenciada, através do estímulo aos sentidos, aproximando o vínculo entre o homem e a natureza (CORNELL, 2008; MENDONÇA, 2000). As trilhas sensitivas exploram os órgãos dos sentidos, reeducando a visão, o sentido predominante na atualidade. No mesmo momento em que se vivencia essa relação com o espaço, despertam sentimentos em relação a ele, fazendo com que ocorra a transformação de valores em relação a ele (SILVA; FIGUEIREDO, 2011).

Nesse sentido, as trilhas sensitivas aproximam-se da proposta das trilhas perceptivas, denominadas por Matarezi (2006) de Trilhas da Vida. Nas trilhas perceptivas, as atividades são realizadas com as pessoas de olhos vendados, 
excluindo a visão, estratégia utilizada para colocar os participantes em situação de estranhamento e para despertar os demais sentidos que se encontram adormecidos, conforme menciona o autor. Contudo, neste estudo, a visão também será foco de reeducação.

Participar de uma trilha interpretativa, por sua vez, é promover discussões sobre o lugar onde vivemos, despertadas a partir de vivências que levam as pessoas a pensarem sobre si e sobre o outro. Desse modo, reflete-se e aprende-se sobre o que se encontra ao nosso redor. De acordo com Stranz e Larratea (2006) apud Silva e Figueiredo (2011, p. 129),

[...] aliadas aos princípios da Educação Ambiental, as trilhas interpretativas devem favorecer as observações do meio biótico e abiótico, estimulando os visitantes à percepção e à integração com a natureza; precisam ser bem planejadas com uma dinâmica de observação, reflexão e sensibilização subjetiva, além da diversificação de atividades. É através dessa experiência que os indivíduos são levados a um reconhecimento de seus espaços vividos, graças à identificação de preferências, motivações e valores paisagísticos, sendo também um instrumento pedagógico, já que proporciona a aproximação da realidade a diversas temáticas discutidas no ambiente escolar.

Além disso, as trilhas interpretativas possibilitam a construção de valores como cooperação, convivência e diversidade pessoal. As trilhas interpretativas "são exemplos de atividades formativas e informativas que provocam novos processos de adaptação e de assimilação, relativos ao desenvolvimento de experiências e de conhecimentos estruturados em relação ao meio ambiente (PAIVA; FRANÇA, 2007, p. 112).

Entende-se que "o papel da trilha não é definir conceitos, mas vivenciá-los, percebê-los, significá-los” (MATAREZI, 2006, p. 194). Ainda, segundo Paiva e França (2007, p. 120):

A trilha é o mundo dos sentidos a ser explorado como facilitador do desenvolvimento de uma consciência crítica. Somente é possível valorizar as experiências ambientais durante o percurso de uma trilha interpretativa como educativas e vivenciais na medida em que estejam vinculadas a uma visão ecológica na qual o sentimento de ser parte seja priorizado.

Portanto, o objetivo dessa pesquisa foi analisar contribuições de vivências em trilhas sensitivas e interpretativas em relação à formação ambiental de estudantes do $5^{\circ}$ ano do Ensino Fundamental de uma escola da cidade de Lajeado/RS/ BRA. Espera-se que essa investigação auxilie contextos educativos a perceberem a potência educativa da experiência direta com a natureza e da necessidade da problematização do contexto no qual os estudantes vivem, como caminho para a formação de sujeitos conscientes e ativos quanto à sua responsabilidade ambiental.

\section{DEFININDO O PERCURSO METODOLÓGICO}

Essa pesquisa, que se caracteriza como qualitativa, foi desenvolvida a partir da relação dialógica entre os pesquisadores e os sujeitos participantes, proporcionando 
aprendizagens a ambos, bem como, a construção e o compartilhamento de conhecimentos a respeito do tema meio ambiente.

Ela foi realizada numa escola de Ensino Fundamental de Lajeado/RS/BRA, com uma turma de $5^{\circ}$ ano do Ensino Fundamental, composta por 15 estudantes de ambos os sexos. A definição da turma ocorreu a partir do diálogo com a 3 . $^{a}$ Coordenadoria Regional de Educação ( $3{ }^{a} \mathrm{CRE}$ ), órgão responsável pela gestão das escolas da rede estadual do Vale do Taquari/RS/Brasil.

A escolha da instituição e da turma decorreu da indicação da $3{ }^{a}$ CRE, bem como, do interesse manifestado pela equipe diretiva e da coordenação pedagógica da escola. A aproximação do contexto de estudo iniciou em novembro de 2017, quando ocorreu a primeira visita à escola. Nesta data foi explicitado o tema da pesquisa à equipe diretiva, discutiram-se possíveis locais para a realização das trilhas e se definiu a turma. A coordenadora pedagógica da escola solicitou a participação dos pesquisadores numa das reuniões escolares, que ocorreu em 03 de abril, no início do ano letivo de 2018, para a apresentação do projeto a toda a equipe de professores.

A turma disponibilizada, $5 .^{\circ}$ ano, tinha caráter unidocente, ou seja, a professora titular era responsável pelo ensino de todas as áreas de conhecimento. Foram disponibilizados os horários das aulas de Educação Física para a realização das trilhas. Foram realizadas três vivências, que ocorreram nos dias 11,18 e 25 de abril de 2018, em três lugares diferentes (Figura 1): a praça do bairro onde a escola está localizada, o Jardim Botânico de Lajeado/RS/BRA e a própria escola. As trilhas duraram de 2 horas a 3 horas e 20 minutos. As vivências foram orientadas pelos pesquisadores, com formação em Educação Física - Licenciatura, e acompanhadas pela professora titular dos estudantes, com formação em História - Licenciatura.

Figura 1: Locais onde as trilhas foram realizadas

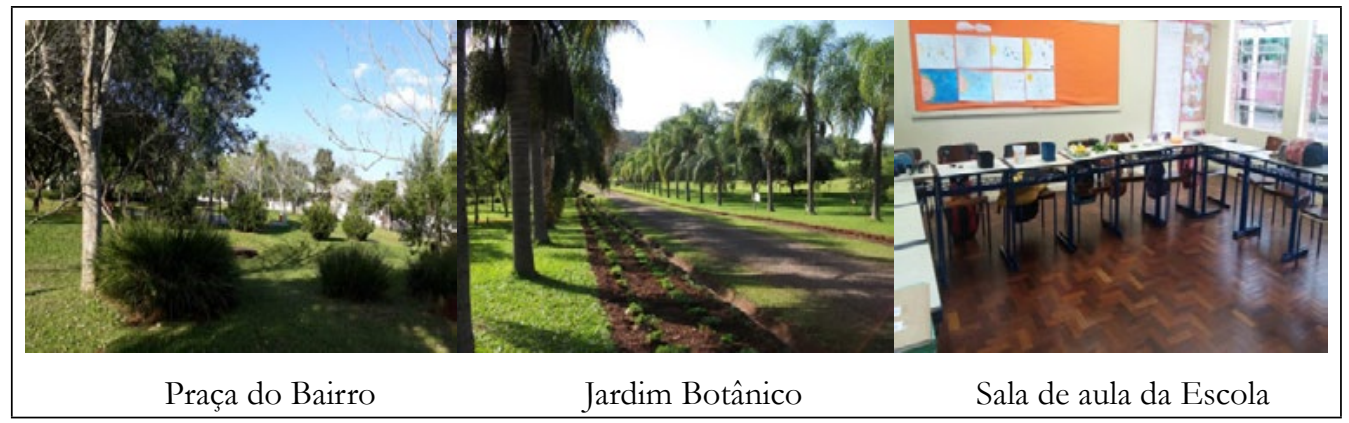

Fonte: Autores.

Em relação à coleta de informações, o ponto de partida foi o Projeto Político Pedagógico (PPP), no qual se analisou como a escola propõe o tema meio ambiente na formação dos estudantes. Em seguida, antes das vivências, aplicou-se um questionário aos 15 estudantes do $5^{\circ}$ ano, para procurar conhecer experiências educativas que já tiveram, relacionadas à Educação Ambiental. Em relação às 
trilhas, a coleta de informações ocorreu por meio de produção de cartazes nos quais expressaram suas percepções acerca das experiências e contribuições para sua formação ecológica. Os pesquisadores utilizaram o diário de campo, acrescido de informações oriundas da gravação das rodas de conversa ao final das trilhas. Além disso, foram realizados registros fotográficos dos lugares das vivências e dos cartazes produzidos.

Em relação às informações, realizou-se uma análise textual qualitativa, com base na proposta de Moraes (2007). Para o autor, a análise textual qualitativa é um processo de aprofundamento de processos discursivos a partir da leitura de materiais textuais, objetivando "descrevê-los e interpretá-los no sentido de atingir uma compreensão mais elaborada dos fenômenos e dos discursos no interior dos quais foram produzidos" (MORAES, 2007, p. 89). A partir da análise textual, foram definidas duas categorias: a primeira aborda a proposta de Educação Ambiental na escola e a segunda trata das contribuições das trilhas para a formação ecológica dos estudantes.

Em relação aos cuidados éticos, como os estudantes eram todos menores de idade, eles assinaram um Termo de Assentimento e seus responsáveis assinaram o Termo de Consentimento Livre e Esclarecido, autorizando a participação deles. Devido ao zelo pela identidade dos participantes, utilizamos os códigos "estudante 1, estudante 2...”. O projeto de pesquisa foi aprovado no Comitê de Ética da Univates $^{3}$.

\section{DANDO O PRIMEIRO PASSO: ANÁLISE DA PROPOSTA DE FORMAÇÃO ECOLÓGICA DOS ESTUDANTES NA ESCOLA}

No PPP da escola (ESCOLA, 2016), o meio ambiente é apresentado como tema transversal. Ele transcende os aspectos físicos e biológicos, englobando também aspectos sociais, pois entende-se que o ser humano também faz parte da natureza. A preocupação da escola também é trabalhar a autonomia e a responsabilidade dos estudantes. Destaca que é preciso refletir com o educando sobre como devem ser as relações do homem com o ambiente em que vive, para poderem tomar decisões adequadas na direção das metas desejadas: o crescimento cultural, a qualidade de vida e o equilíbrio ambiental. Acredita-se na necessidade de proporcionar aos estudantes o contato com espécies de plantas nativas da região onde vivem, incentivando-os ao plantio destas plantas.

No contexto educacional brasileiro, o meio ambiente foi apresentado pelos Parâmetros Curriculares Nacionais como tema transversal, em 1997, no ano seguinte à homologação da Lei de Diretrizes e Bases da Educação Nacional. A partir desse momento, a questão do meio ambiente ganha caráter de urgência e orientase que seja um conhecimento que perpasse todas as disciplinas e áreas (BRASIL, 1997). Em 1999, com a Lei n. 9 9.795, institui-se que "A educação ambiental é um

3 Projeto aprovado no Comitê de Ética da Univates. Parecer n. ${ }^{\circ} 2.476 .814$ de 29/01/2018. 
componente essencial e permanente da educação nacional, devendo estar presente, de forma articulada, em todos os níveis e modalidades do processo educativo, em caráter formal e não-formal” (BRASIL, 2005, p. 65).

Antes de as trilhas serem propostas, buscou-se entender como era desenvolvido o tema meio ambiente na escola onde estes sujeitos estão inseridos. Em conversa com a coordenadora pedagógica constatou-se que

[...] esse assunto é trabalhado frequentemente com os estudantes, por meio de saídas de campo e em alguns projetos. Ela comentou que as saídas têm diminuído muito, principalmente as viagens mais longas, porém ainda se mantêm as viagens para locais mais próximos, tal como o Jardim Botânico do município (Diário de campo, 03/04/2018).

Ao tomar como referência estudos que tratam da implantação da Educação Ambiental nos currículos escolares, tais como os realizados na Polônia (GAJUSLANKAMER, 2004), Espanha (CONDE; SÁNCHEZ, 2010) e Inglaterra (CHATZIFOTIOU, 2006), percebe-se que, semelhante ao Brasil, a preocupação com o ambiente passou a ocorrer a partir de 1990. Outro aspecto em comum é a ideia de transversalidade, ou seja, que a responsabilidade pelo desenvolvimento do tema meio ambiente não fique restrito a uma disciplina ou área do conhecimento. No entanto, há disciplinas, tais como a Biologia, a Geografia, a Química, que se destacam nas ações educativas relacionadas a esta temática, incluindo também conteúdos relacionados ao meio ambiente na sua programação tradicional. Dessa forma, percebe-se que áreas como a Educação Física, de acordo com Neuenfeldt (2016), que trabalha com práticas corporais, têm tido dificuldade de desenvolver esse tema a partir de sua especificidade, apesar de aderir aos projetos propostos pela escola.

$\mathrm{Na}$ reunião realizada com a coordenadora pedagógica, direção e professores de História, Educação Física, Letras, Matemática, Biologia, Artes, foi percebível que os professores entendem a importância desse tema para os estudantes. Uma professora relatou sua experiência:

Acho muito bacana trabalhar esse assunto. Uma vez fomos visitar a casa do avô de um estudante que ficava no interior e fiquei encantada do quão criativos os estudantes tornam-se. De acordo com sua imaginação, criaram casinhas de bambu, onde imaginavam que estavam numa espécie de filme tipo Jurassic Park, que viriam bichos, etc. Outros imitavam bichos, rolavam no chão. Era incrível como eles tinham liberdade, autonomia para criar e brincar naquele espaço (Diário de campo, 03/04/2018).

Nesta fala, percebe-se que o contato com a natureza possibilita ir além de sensibilizar o sujeito quanto às questões ambientais, pois também proporciona a liberdade de criação dele naquele espaço, com os objetos e seres vivos que ele tem à disposição, bem como, desenvolve a autonomia e a imaginação. Schwartz (2006) enfatiza a necessidade dos indivíduos de procurar atividades de lazer, que, pelas suas características, liberdade, prazer, alegria..., impactam diretamente a qualidade de vida. Há um valor intrínseco associado à vida ao ar livre, que não se encontra 
na sociedade urbanizada e industrial e que reflete a forma como os indivíduos entendem e percebem o próprio espaço natural.

Analisando os questionários, percebe-se que alguns estudantes já tiveram alguma vivência fora da escola, visando a temática do meio ambiente: "A gente foi no Jardim Botânico, vimos uma palestra, a cachoeira, foi legal e divertido" (Questionário, Estudante 1, 11/04/2018); "Fomos explorar a mata e ficamos bastante tempo e depois fomos sentir a água, o cheiro da natureza e o que ela tem de bom" (Questionário, Estudante 2, 11/04/2018).

A partir das respostas dos estudantes, percebe-se que o Jardim Botânico é o espaço mais visitado; porém, nas proximidades onde a escola se situa, há uma praça arborizada, que pode ser utilizada para a realização de trilhas. Dessa forma, decidiuse realizar uma trilha na praça perto da escola, para que os estudantes repensem sua relação com o lugar onde vivem; outra, no Jardim Botânico; e mais uma trilha móvel, na própria escola.

\section{DANDO O SEGUNDO PASSO: ANALISANDO CONTRIBUIÇÓES DAS TRILHAS NA FORMAÇÃO ECOLÓGICA DOS ESTUDANTES}

Ao definir os locais para a realização das trilhas, reitera-se que se partiu do pressuposto de que ambientes próximos à escola, como a praça do bairro, deveriam fazer parte da experiência dos estudantes, instigando-os a olharem de forma crítica para a relação que estabelecem com o meio no qual vivem. Logo, a primeira vivência ocorreu numa praça localizada a cerca de 500 metros do educandário.

De acordo com Melazo (2005, p. 47),

[...] devemos entender a cidade como um "organismo vivo", que depende de
todos os seus órgãos em bom funcionamento, interligados em um processo
de equilíbrio e harmonia. Essa interdependência está relacionada aos aspectos
naturais relacionados à reprodução do espaço seja no setor habitacional,
comercial, industrial, de lazer, etc. O agente responsável por esse equilíbrio
ou desequilíbrio é o homem e suas respectivas ações. Nesse sentido, o meio
ambiente e o homem tornam-se protagonistas de uma importante relação
de interdependência, que têm como "palco" dessas relações, o meio em que
vivem, as cidades.

A primeira trilha realizada denomina-se "Trilhas de Surpresas" (CORNELL, 2008). Nesta trilha, os estudantes tiveram que localizar objetos não naturais colocados pelos pesquisadores entre plantas num trajeto de 20 metros. Nessa atividade, os estudantes estavam ansiosos por começar e localizar os objetos artificiais. Durante a caminhada pela trilha, percebeu-se que a empolgação foi grande e, devido à ânsia de encontrar os objetos, estes passavam despercebidos por eles, pois "pedimos quantas coisas eles acharam, mas nenhum estudante encontrou todos que foram colocados naquele local" (Diário de campo, 11/04/2018).

Após todos terem passado uma vez pelo percurso, voltamos ao início da trilha e juntos fomos procurar os objetos. Na segunda tentativa, conseguiram encontrar aqueles que não tinham visto. Mas, "desta vez, eles encontraram até coisas que não 
foram colocadas por nós [...]. Juntamos todos os objetos e discutimos a questão de que aquele não era local para colocarmos lixo; contudo, identificamos que o descarte de materiais de difícil decomposição ocorria de forma inadequada" (Diário de campo, 11/04/2018).

Após, ao voltar, realizou-se uma "Trilha Urbana". Os estudantes foram orientados a observar as ruas, casas, jardins, no trajeto da praça até a escola. Percebiam aspectos que poderiam ser melhorados em relação à ação humana. "Os estudantes encontraram muito lixo pela rua, chegando a se surpreenderem com a quantidade. Eles perceberam coisas que estavam compondo o cenário que durante a ida não notaram, passaram a olhar o trajeto até a escola com outros olhos" (Diário de campo, 11/04/2018).

A interpretação ambiental pode traduzir-se em atividade educativa, quando há contato direto com o recurso que está sendo interpretado. Esse contato viabiliza novas experiências e revela significados com o uso de objetos originais. Assim, as trilhas são instrumentos a serem utilizados de maneira multidisciplinar, articulando diversas áreas do saber, propiciando abordagens transversais da temática ambiental, bem como, a conscientização dos sujeitos envolvidos (PAIVA; FRANÇA, 2007).

Assim, percebe-se que as trilhas proporcionadas nesse dia sensibilizaram os estudantes para um olhar mais atento às imediações do contexto escolar, local onde vivem. Bruhns (2006) propõe a prática da caminhada, pois possibilita a reflexão sobre o espaço e sobre o envolvimento do caminhante com esse espaço, bem como, colabora com processos de revisão e de redimensionamento de aspetos da realidade. Ao optarmos pelas trilhas, compartilha-se com o entendimento da autora de que "o envolvimento com o ambiente no qual ocorre a caminhada torna-se mais acentuado e duradouro quando comparado com atividades em que o impacto do instantâneo faz-se presente, como é o caso das descidas em corredeiras com botes infláveis" (BRUHNS, 2006, p. 27).

$\mathrm{Na}$ caminhada, de acordo com Bruhns (2006), a experiência sensível é pessoal, combinando prazer estético e desejo de conhecimento. Aguçam-se os sentidos num meio ambiente que rompe regras formais de eufonia e estéticas e induz a contemplação. $\mathrm{Na}$ caminhada, um corpo move-se com liberdade, a qual permite a escolha para perceber, sentir e tocar o meio ambiente.

Para finalizar a primeira vivência, na sala de aula da escola, os estudantes foram organizados em grupos e construíram cartazes (figura 2), onde escreveram e desenharam aspectos que representavam o que lhes havia tocado, instigando-os a pensar sobre o local em que eles vivem e a relação que estabelecem com ele. 
Figura 2: Cartazes produzidos pelos estudantes após a primeira vivência.

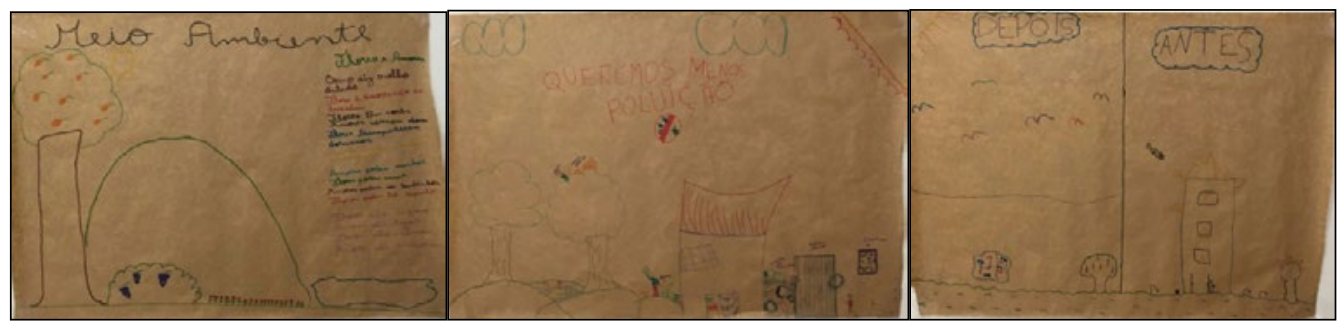

Fonte: Autores.

Analisando os cartazes, constata-se que a "Trilha de Surpresas" e a "Trilha Urbana" sensibilizaram os estudantes sobre o ambiente em que vivem. Eles destacaram aspectos como: "Lixo fora da lixeira, árvores cortadas, galhos nas calçadas" (Diário de campo, 11/04/2018). Ao comentarem os registros dos cartazes, os estudantes frisaram: "nosso cartaz tem árvores, flores, pássaros... mas não foi desse jeito que estava na praça. Lá tinha muito lixo no chão, árvores quebradas, pássaros mortos" (Estudante 9, 11/04/2018); "Nós desenhamos uma parte boa e uma, ruim, uma era o meio ambiente limpo, a outra éramos nós desrespeitando" (Estudante 12, 11/04/2018). Essas manifestações permitem dizer que a vivência auxiliou os estudantes a enxergarem o meio em que vivem com um olhar mais crítico.

Logo, concorda-se com Duarte Júnior (2010), que menciona que se passa por uma crise de sentidos, resultado do estilo moderno de viver, que foi influenciado pelos valores da modernidade. A cidade deve ser entendida como espaço integrante da natureza, que, assim como a natureza, deve ser respeitada e conservada. $\mathrm{O}$ ato simples da caminhada, hoje em dia, tornou-se uma espécie de "obrigação", tanto que é comum as pessoas caminharam utilizando um aparelho tecnológico, impedindoas de ouvir os sons ao redor. Dessa forma, acabam ignorando as árvores, flores, pássaros e tudo mais que a natureza e o ambiente nos mostram.

Analisando o sentido da visão, Duarte Júnior (2010) percebe-o como superestimulado pela atual sociedade das imagens, o que o direciona e o condiciona a uma percepção restrita do mundo, na maioria das vezes, construída a partir dos meios de comunicação, em vez de ser estimulado pelo contato direto, pela experiência direta. Não se nega o valor da representação das coisas, mas a preocupação é com a valorização extrema dada ao mundo das imagens, que nos torna cegos e indiferentes a tudo.

Os resultados dessa pesquisa mostram que, mesmo com a supervalorização da visão, é necessária a reeducação do olhar. Na primeira trilha, os estudantes passaram e não viram os objetos inseridos entre as plantas. Contudo, uma discussão e uma análise mais cuidadosa do ambiente despertou o olhar atento e crítico dos estudantes no retorno à escola. Duarte Júnior (2010) defende uma educação do 
sensível, denominada de educação estética, relativa à capacidade de o ser humano sentir a si mesmo e ao próprio mundo em um todo integrado:

[..] é preciso possibilitar às pessoas a descoberta de cores, formas, sabores, texturas, odores, educando o olhar, a audição, o tato, o paladar e o olfato. Isso pode ser feito pelo contato com obras de arte, da arte culinária, das paisagens e noites estreladas, das frutas colhidas e saboreadas "no pé", das caminhadas por trilhas e bosques (p. 14).

A segunda vivência aconteceu no Jardim Botânico de Lajeado. Como primeira atividade, sustentada em Bruhns (2006) que defende a caminhada como forma de estabelecer contato com o mundo, "fomos conhecer os viveiros onde se cultivam mudas de árvores nativas, exóticas e flores destinadas à arborização da cidade. Explicamos aos estudantes que as mudas e as variedades de plantas que eram cultivadas podem ser compradas a um valor abaixo do preço de mercado. Ressaltamos que o coqueiro é uma árvore nativa da região; já o plátano é uma árvore exótica, pois não é nativa. A partir dessas informações, alguns estudantes conseguiram relacionar as espécies existentes com as plantas que tinham em casa" (Diário de campo, 18/04/2018).

Em seguida, iniciamos o trajeto da Trilha da Cascata, que é uma trilha autoguiada, mas foi conduzida pelos pesquisadores. Os pesquisadores comentaram que "entraremos na floresta e isso exige concentração, pois passaremos por uma trilha cujo chão é irregular, tem obstáculos, pedras, galhos, o chão é escorregadio, o silêncio é importante para ouvirmos os pássaros" (Diário de campo, 18/04/2018).

Após caminhar alguns minutos, realizou-se a vivência denominada "Passeio da Lagarta" (CORNELL, 2008). É uma trilha na qual os estudantes foram organizados em fila indiana. Cada um deles colocou as mãos nos ombros do colega da frente e foram conduzidos por um dos pesquisadores, que estava no início da fila, pela trilha na mata. O percurso levou em torno de vinte minutos. "Os estudantes foram vendados e trabalhamos o sentido do tato com os pés, a audição, assim como a cooperação, pois teriam que confiar muito no seu colega" (Diário de campo, 18/04/2018).

Nessa atividade, percebeu-se a preocupação dos estudantes com o colega que vinha atrás. Eles alertavam: "Cuidado que aqui tem uma pedra"; "agora tem uma raiz de árvore"; "vem devagar porque está liso" (Diário de campo, 18/04/2018). Além de trabalhar a questão sensorial, essa trilha oportunizou a emergência de valores, como a cooperação e a percepção da interdependência do outro, indispensável para a formação ambiental.

A Educação Ambiental deve estar relacionada com a construção de uma nova visão de mundo coletiva, comprometida com o outro, que promova "a conscientização que se dá na relação entre o 'eu' e o 'outro', pela prática social reflexiva e fundamentada teoricamente” (LOUREIRO, 2004, p. 29).

"Ao chegarem às margens da cascata, os estudantes retiraram as vendas e sentaram-se no chão, em pedras ou galhos das árvores, contemplando a cascata presente no local" (Diário de campo, 18/04/2018). Nesse contexto, realizou-se 
a atividade "Evocação de Palavras". Solicitou-se que cada um escolhesse uma palavra ou frase que expressasse o significado da vivência e a registrasse num papel. Permaneceram em torno de 10 minutos nesse local, admirando e sentindo a natureza. "Um menino se deitou sobre uma pedra e por lá ele ficou até voltamos" (Diário de campo, 18/04/2018). As palavras mais citadas foram: "Diversão", "ar puro", "alegria”, "amor", "paixão pela natureza”, "inspiração" (Figura 3).

Figura 3: Atividade realizada no Jardim Botânico - Evocação de Palavras.

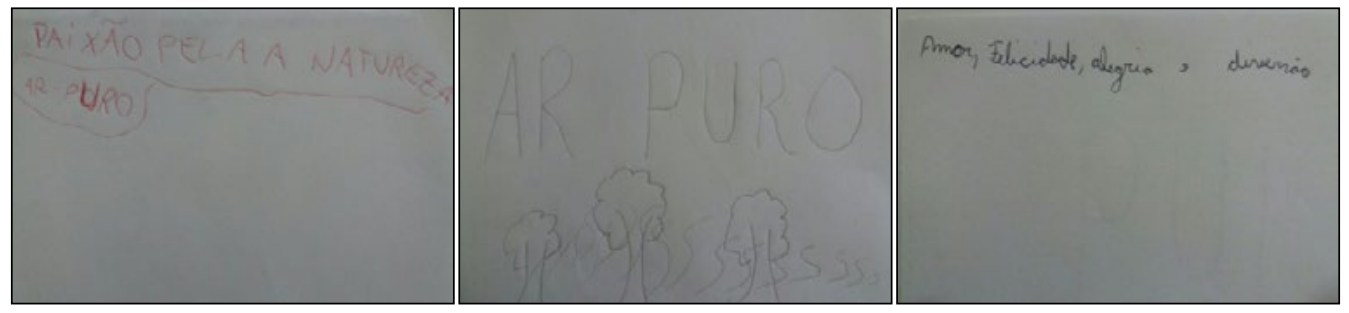

Fonte: Autores.

Nesse dia, os estudantes tiveram um tempo de reflexão, de conexão com o ambiente natural, o que se evidencia nas seguintes falas: "eu senti aquele cheirinho da natureza, o ar puro, uma coisa que é diferente da cidade" (Estudante 1, 18/04/2018); "Percebi os sons diferentes daqui e da cidade. Porque na cidade tem muito barulho de carro, de moto, de caminhão. Aqui não, aqui tem pássaros, cachoeira" (Estudante 5, 18/04/2018).

Em estudo sobre o uso de trilhas para a melhoria da relação ser humanonatureza, Pasqualeto e Melo (2007) também constataram que as pessoas, de alguma forma, foram sensibilizadas ao realizarem o percurso da trilha. Os participantes manifestaram íntima relação com os ecossistemas e a interdependência que se estabelece entre o ser humano e a natureza.

Nesse sentido, a proposta das trilhas vai ao encontro dos conceitos de Educação Ambiental, na perspectiva crítica, transformadora e emancipatória, tais como: autonomia, pertencimento, alteridade, identidade, complexidade, transdisciplinaridade, potência de ação, participação, sustentabilidade, entre outros, (MATAREZI, 2006).

O fato de os estudantes irem a um lugar diferente da escola deixou-os entusiasmados. Muitos deles já estiveram no Jardim Botânico, porém relataram que "a gente foi no Jardim Botânico e tivemos uma palestra, agora fomos ver a cachoeira e as plantas" (Estudante 5, Questionário, 11/04/2018). Portanto, esta foi, para muitos, a primeira vez que fizeram atividades que exploraram a relação homem-natureza a partir do corpo.

Nesse sentido, cabe a reflexão: Por que o corpo tem tido pouco espaço na formação ambiental, no contexto escolar? O domínio de conceitos centrais da área da Educação Ambiental é extremamente relevante; contudo, Neuenfeldt e Mazzarino (2016) defendem que o conhecimento de metodologias de ensino que 
valorizem vivências com a natureza e que reconheçam o corpo como lugar de aprendizagem também é essencial:

\begin{abstract}
Portanto, pensar o corpo como lugar onde a experiência da Educação Ambiental nos toca pode ser uma alternativa para conseguir mudanças de atitudes, frente à atual crise ambiental. Isso implica reconhecer que o homem é parte constituinte da natureza, opondo-se à perspectiva de objetificação da natureza e do próprio corpo. É compreender que cada sujeito constrói a sua própria experiência e que a "ideia da coisa não substitui a coisa propriamente dita", como bem mencionou Merleau-Ponty (1999) (NEUENFELDT; MAZARRINO, 2016, p. 34).
\end{abstract}

Para finalizar essa vivência, após o retorno da Trilha da Cascata, foi realizada uma roda de conversa. Os estudantes foram questionados sobre o que poderia ser feito para preservar o meio ambiente. Eles foram pontuais dizendo: "não jogar lixo nos rios, no chão, não quebrar as árvores, não desmatar..." (Estudante 4, 18/04/18). Nesse momento, refletiu-se sobre as diferenças entre os dois locais das vivências já realizadas, a praça perto da escola e o Jardim Botânico, e os estudantes destacaram: "Aqui tem menos lixo. Nem tem lixo, porque tem a placa dizendo para não poluir" (Estudante 3,18/04/2018). Motivamos os estudantes a pensarem um pouco mais e completamos: "Mas na cidade também tem placas e mesmo assim as pessoas poluem" (Diário de campo, 18/04/2018). Prontamente um estudante disse: "Aqui tem um guarda que fica cuidando, na cidade não" (Estudante 5, 18/04/2018).

A partir do relato dos estudantes cabe a reflexão: as trilhas realizadas no Jardim Botânico sensibilizaram os estudantes? Nem toda vivência torna-se uma experiência. Torna-se experiência aquela que nos toca, que nos faz refletir, que nos desacomoda, que nos torna diferentes, conforme nos diz Larrosa (2002, p. 40): "A experiência é sempre de alguém, subjetiva, é sempre daqui e de agora, contextual, finita, provisória, sensível, mortal, de carne e osso, como a própria vida". Defendese que as trilhas têm potencial sensibilizador e reflexivo no que toca à formação ambiental dos estudantes e espera-se que, enquanto cidadãos, percebam que fazer o que é certo independe de ter ou não fiscalização.

A terceira vivência nasceu da provocação de uma professora na primeira reunião realizada na escola: "Mas como vão fazer uma vivência na natureza se na escola não tem nenhum espaço verde?” (Diário de campo, 03/04/2018). A resposta veio com a realização de uma trilha móvel na escola.

Para Matarezi (2001), a trilha móvel consiste na simulação de um ambiente natural de Floresta Atlântica ou outro bioma dentro de escolas, parques ou eventos. Aqui se inverte a condição inicial das pessoas se deslocarem ao encontro da "floresta"; agora é a "floresta" que se desloca ao encontro dos grupos de pessoas. Assim, os pesquisadores construíram uma trilha móvel na sala de aula da escola (figura 1). As mesas foram organizadas uma ao lado da outra para poder apoiar dez caixas em cima delas nas quais foram colocados elementos naturais da região onde vivem os estudantes. Os elementos utilizados para o desenvolvimento da atividade foram: pedras, terra, água, folhas de laranja e limão, cebola, butiá, repolho, laranjas e limão. Cada um desses elementos estava distribuído numa caixa. Os estudantes 
foram vendados e conduzidos individualmente pelos pesquisadores pelo percurso construído. Através do tato, do olfato e do paladar, eles tiveram contato com os elementos que estavam nas caixas.

Para muitos estudantes, não poder ver foi extremamente difícil. Em certo momento da atividade, "havia uma fruta que ninguém tinha acertado, porém falavam que tinha uma colega que iria acertar. Ela, pelo tato, conseguiu distinguir, porém pediu para cheirar para ter certeza" (Diário de campo, 25/04/2018). Para finalizar a atividade, realizou-se uma roda de conversa, na qual perguntou-se: "Por que somente a colega acertou?" (Diário de campo, 25/04/2018). Os estudantes argumentaram que "era pelo fato de morar no interior e ter essa fruta em casa" (Diário de campo, 25/04/2018).

Assim como os adultos, as crianças constroem sua própria visão de mundo e são influenciadas pelo meio onde vivem. Porém, a dificuldade de reconhecer alguns elementos sem a visão foi notória: "havia coisas que tinha na casa de todos ou em mercados, que em algum momento já haviam tocado, sentido o cheiro ou sabor, mas não conseguiram identificar" (Diário de campo, 25/04/2018). Ou, como disse um estudante: "verdade, a cebola está sempre na comida da minha mãe e eu não adivinhei, repolho eu adoro comer e também não acertei" (Diário de campo, 25/04/2018).

A trilha móvel permite a realização de atividades sensitivas e interpretativas sem ter que levar os estudantes para fora da escola, possibilitando-lhes a reflexão sobre o meio em que eles vivem: "Com as trilhas percebi a importância de ver e sentir, no primeiro passeio tinha que observar as plantas, árvores, lixos... agora tinha que tocar, às vezes, sem olhar eu não sei o que é, por isso tenho que tocar" (Questionário, 25/04/2018).

Portanto, as trilhas possibilitam que os estudantes reflitam sobre o meio em que vivem e percebam a interdependência do homem com a natureza. Para Matarezi (2001), as trilhas perceptivas e interpretativas caracterizam-se como um experimento educacional transdisciplinar, que integra objetivos educacionais e conservacionistas. Partindo do campo da Educação Ambiental, o autor busca promover uma reaproximação dos participantes com o meio ambiente nos seus aspectos naturais, sociais, culturais e históricos e, por esta via, estimular uma reflexão crítica das interações históricas entre a sociedade, o indivíduo e o lugar onde vive. Essa interação ocorre por meio de vivências em grupo, nas quais as pessoas experimentam diferentes situações de olhos vendados e descalças, exercendo intensamente o tato, o olfato, o paladar e a audição.

Em relação às trilhas, de acordo com Neuenfeldt (2016), pode-se afirmar que as vivências com a natureza possibilitam uma abertura para a experiência e formas de exploração dos sentidos, reforçando a importância do corpo em processos de ensino e de aprendizagem. É necessário possibilitar essa exploração e novas experiências aos estudantes e trabalhar a Educação Ambiental de forma que ultrapasse os limites das disciplinas e das hierarquias das áreas de conhecimento, para ampliar nossa capacidade perceptiva dos diversos níveis de realidade e de 
complexidade, alimentando nosso imaginário e o sonho coletivo de um mundo melhor.

\section{FINAL DO PERCURSO: O QUE APRENDEMOS?}

O presente estudo evidenciou que trilhas sensitivas e interpretativas contribuem para a formação ambiental dos estudantes. Não só ao conscientizálos dos seus atos em relação à natureza, mas também trabalham valores como a cooperação, essencial para o convívio em sociedade.

As trilhas contribuíram para despertar e aprimorar os sentidos e percepções, tornando os estudantes críticos. Foi perceptível a necessidade da reeducação da visão e dos demais sentidos corporais. A experiência direta com a natureza possibilitou aos estudantes conhecerem melhor o meio ambiente onde vivem, repensarem o lugar que cada um ocupa na sociedade e refletirem sobre como se relacionam com a natureza. A experiência também os auxiliou a olharem para a natureza de modo diferente, compreendendo que eles também fazem parte dela.

Por outro lado, entende-se que, ao trabalhar as trilhas sensitivas e interpretativas em diferentes locais (praça, rua, Jardim Botânico, sala de aula), demonstram-se à escola, possibilidades de alternativas metodológicas para trabalhar a Educação Ambiental. Muitos contextos educativos, pelo fato de não terem espaço natural, acreditam que não há possibilidade de trabalhar esse tema. Entretanto, é possível trazer elementos da natureza para uma sala de aula através de trilhas móveis, ampliando a formação ambiental para além dos aspectos conceituais

Portanto, essa pesquisa, ao propor trilhas sensitivas e interpretativas em contextos urbanos e na própria escola, contribuiu com a formação ambiental dos estudantes. Constatou-se que é importante promover experiências que os desacomodem e que os façam sentir e refletir.

Uma questão que cabe destacar é que se trabalhou com estudantes de $5^{\circ}$ ano, etapa em que os estudantes ainda gostam e querem brincar. Assim, essa aproximação com a ludicidade é um fator que deve ser considerado ao propor as trilhas, justificando os nomes dados por Cornell (2008) a algumas delas, como "Trilha de Surpresas" e "Passeio da Lagarta". Concorda-se com o autor que defende que as vivências com a natureza devem ser experiências prazerosas.

Sugere-se como continuidade da pesquisa analisar se o envolvimento de professores de diversas áreas do conhecimento durante as trilhas e no planejamento delas podem contribuir para a compreensão de conceitos teóricos relacionados à temática ambiental. 


\section{REFERÊNCIAS}

ALVES, Ruben. O amor que acende a lua. Campinas, SP: Papirus: Speculum, 1999.

BRUHNS, Heloisa Turini. Ecoturismo e caminhada: na trilha das ideias. In.: MARINHO, Alcyane; BRUHNS, Heloisa Turini (Org.). Viagens, lazer e esporte. Barueri: Manole, 2006. p. 27-42.

CARVALHO, Isabel Cristina de Moura. Educação Ambiental: a formação do sujeito ecológico. 8. ed. São Paulo: Cortez, 2008.

BRASIL. Parâmetros Curriculares Nacionais: meio ambiente e saúde. Vol. 09. Brasília: MEC/SEF, 1997.

. Programa Nacional de Educação Ambiental. 3 ed. Brasília: Ministério do Meio Ambiente, 2005. Disponível em: <http://www.mma.gov.br/educacao-ambiental/ politica-de-educacao-ambiental/programa-nacional-de-educacao-ambiental $>$. Acesso em: $30 / 07 / 2014$.

CHATZIFOTIOU, Athanasia. Environmental education, national curriculum and primary school teachers. Findings of a research study in England and possible implications upon education for sustainable development. The Curriculum Journal, v. 17, n. 4, dec., p. 367-381, 2006. Disponível em: http://www.tandfonline.com/ $\mathrm{doi} / \mathrm{abs} / 10.1080 / 09585170601072478$ ?journalCode=rcjo20\#preview. Acesso em: $15 / 03 / 2014$.

CONDE, María del Carmen; Sánchez, J. Samuel. The school curriculum and environmental education: A school environmental audit experience. International Journal of Environmental \& Science Education, v. 5, n. 4, p. 477-494, oct., 2010. Disponível em: < http://www.ijese.com/V5N4.htm>. Acesso em: 28/02/2014.

CORNELL, Joseph. Vivências com a natureza 1: guia de atividades para pais e educadores. 3 ed. São Paulo: Aquariana, 2008.

DUARTE JÚNIOR, João Francisco. O sentido dos sentidos. 5 ed. Curitiba: Criar Edições Ltda, 2010.

GAJUS-LANKAMER, Ewa. Environmental Education at Polish Gymnasiums. International Research in Geographical and Environmental Education, v. 13, n. 3, p. 260-276, 2004. Disponível em: http://www.tandfonline.com/doi/ abs/10.1080/10382040408668522\#preview. Acesso em: 02/03/2014.

GIDDENS, Anthony. Para além da esquerda e da direita. O futuro da política radical. São Paulo: Editora da Universidade Estadual Paulista, 1996.

GRÜN, Mauro. Ética e Educação Ambiental: a conexão necessária. 14. ed. Campinas, SP: Papirus, 2011. 
LARROSA, Jorge. Notas sobre a experiência e o saber de Experiência. Revista

Brasileira de Educação. São Paulo, n. 19, jan./fev./mar./abr., p. 20-28, 2002.

LOUREIRO, Carlos Frederico. Trajetória e Fundamentos da Educação Ambiental. São Paulo: Cortez, 2004.

MATAREZI, José. Trilha da vida: (re)descobrindo a natureza com os sentidos. Ambiente \& Educação. Rio Grande (RS): Fundação Universidade do Rio Grande, v. 5/6, p. 55-67, 2001.

Despertando os sentidos da Educação Ambiental. Educar, Curitiba, n. 27, p. 181-199, 2006. Disponível em: <www.scielo.br/pdf/er/n27/a12n27.pdf >. Acesso em: $25 / 07 / 2014$.

MEDEIROS, Aurélia Barbosa. A Importância da educação ambiental na escola nas séries iniciais. Revista Faculdade Montes Belos, São Luis de Montes Belos, v. 4, n. 1, set., p. 01-17, 2011. Disponível em: <http://www.terrabrasilis.org.br/ecotecadigital/ pdf/a-importancia-da-educacao-ambiental-na-escola-nas-series-iniciais.pdf $>$ Acesso em: 03/03/2019.

MELAZO, Guilherme Coelho. Percepção ambiental e educação ambiental: uma reflexão sobre as relações interpessoais e ambientais no espaço urbano. Olhares \& Trilhas. Uberlândia, Ano VI, n. 6, p. 75-51, 2005.

MENDONÇA, Rita. A experiência na natureza segundo Joseph Cornell. In: SERRANO, C. (Org.). A educação pelas pedras: ecoturismo e educação ambiental. São Paulo: Chronos, 2000.

MORAES, Roque. Mergulhos discursivos: análise textual qualitativa entendida como processo integrado de aprender, comunicar e interferir em discursos. In: GALIAZZI, Maria do Carmo; FREITAS, José Vicente. Metodologias emergentes de pesquisa em Educação Ambiental. Ijuí: Unijuí, 2007. p. 85-114.

NEUENFELDT, Derli Juliano. Educação Ambiental e Educação Física escolar: uma proposta de formação de professores a partir de vivências com a natureza. Lajeado, Centro Universitário UNIVATES, Tese de Doutorado, 2016.

NEUENFELDT, Derli Juliano; MAZZARINO, Jane. Márcia. O corpo como lugar onde a experiência da educação ambiental nos toca. Revista Eletrônica do Mestrado em

Educação Ambiental, Rio Grande, n.1, p. 22-36, jan./abr., 2016. Disponível em: http:// https://www.seer.furg.br/remea/article/view/5309/3592. Acesso em: 20/10/2018.

PAIVA, Andréa Carla; FRANÇA, Tereza Luiza de. Trilhas interpretativas: Reconhecendo os elos com a Educação Física. Revista Brasileira de Ciências do Esporte, Campinas, v. 28 , n. 3, p. 109-124, maio, 2007.

SANTIN, Silvino. Educação Física: da alegria do lúdico à opressão do rendimento. 2 ed. Porto Alegre: Edições EST/ESEF - UFRGS, 1996. 
ESCOLA. Projeto Político Pedagógico. Lajeado. 2016.

SILVA, Luciana de Oliveira; FIGUEIREDO, Luiz Alfonso de Vaz. Racionalidades e sensibilidades em trilhas interpretativos-perspectivas promovendo ações formativas de Educação Ambiental na vila de Paranapiacaba. Revista Brasileira de Ecoturismo, São Paulo, v. 4, n.1, p. 25-58, 2011. Disponível em: <http://www.sbecotur.org.br/rbecotur/ seer/index.php/ecoturismo/article/view/73>. Acesso em: 22/10/2017.

SCHWARTZ, Maria Gisele. A aventura no âmbito do lazer: as AFAN em foco. In.:

SCHWARTZ, Maria Gisele (Org.). Aventuras na Natureza: consolidando significados. Jundiaí, SP: Fontoura, 2006. p. 23-33. 